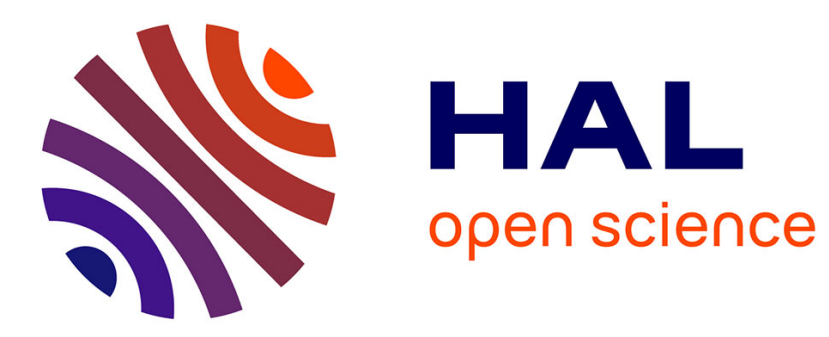

\title{
CAA methodology to simulate turbulence-airfoil noise
} Vincent Clair, Cyril Polacsek, Thomas Le Garrec, Gabriel Reboul

\section{To cite this version:}

Vincent Clair, Cyril Polacsek, Thomas Le Garrec, Gabriel Reboul. CAA methodology to simulate turbulence-airfoil noise. 18th AIAA/CEAS Aeroacoustics Conference (33rd AIAA Aeroacoustics Conference), 2012, Colorado Springs, United States. 10.2514/6.2012-2189 . hal-02085973

\section{HAL Id: hal-02085973 https://hal.science/hal-02085973}

Submitted on 16 Apr 2019

HAL is a multi-disciplinary open access archive for the deposit and dissemination of scientific research documents, whether they are published or not. The documents may come from teaching and research institutions in France or abroad, or from public or private research centers.
L'archive ouverte pluridisciplinaire HAL, est destinée au dépôt et à la diffusion de documents scientifiques de niveau recherche, publiés ou non, émanant des établissements d'enseignement et de recherche français ou étrangers, des laboratoires publics ou privés. 


\title{
CAA methodology to simulate turbulence-airfoil noise
}

\author{
V. Clair*, C. Polacsek ${ }^{\dagger}$, T. Le Garrec ${ }^{\dagger}$ and G. Reboul ${ }^{\dagger}$ \\ ONERA, 92320 Châtillon, France
}

\begin{abstract}
Turbulent wakes generated by turbofan blades and interacting with the outlet guide vanes are known to be mainly contributing to broadband noise emission of aero-engines at approach conditions. Analytical approaches, such as the well-known Amiet model can be adopted to estimate the noise generated by turbulent flows impinging thin airfoils, but they are limited by the flat-plate assumptions. The development of numerical methods allowing to consider more complex geometries and realistic flows is required. The method described in the present paper, is based on a CAA code solving the nonlinear Euler equations. The upstream turbulence is synthesized from a stochastic model and injected into the computational domain through an adapted boundary condition. It is first validated in 2D and 3D against academic flat plate configurations by comparison with Amiet solutions (exact in such cases). Then, 3D computations are applied to simulate the effect of a passive treatment (leading edge serrations) aiming at reducing turbulence interaction noise of an isolated airfoil studied in the framework of European project FLOCON. First calculations on baseline conditions are shown to be able to reproduce the measured spectra and farfield directivities, and the acoustic performances of the serrations (3-4 dB PWL reduction) are fairly well assessed too.
\end{abstract}

\section{Nomenclature}

$\begin{array}{ll}a_{0} & \text { Speed of sound } \\ c & \text { Airfoil chord } \\ g\left(x, k_{x}, k y\right) & \text { Normalized aerodynamic response of the airfoil } \\ \hat{G}(\boldsymbol{x}, \omega \mid \boldsymbol{y}) & \text { Free-field Green's function with uniform flow convection in the frequency domain } \\ k_{x} & \text { Streamwise wavenumber } \\ k_{y} & \text { Spanwise wavenumber } \\ L_{s p a n} & \text { Airfoil span } \\ M=U_{0} / a_{0} & \text { Mach number of the uniform mean flow } U_{0} \\ T_{I} & \text { Turbulence intensity } \\ U_{0} & \text { Uniform mean flow speed } \\ \overline{\boldsymbol{u}}=(\bar{u}, \bar{v}, \bar{w}) & \text { Mean velocity vector } \\ \boldsymbol{u}^{\prime}=\left(u^{\prime}, v^{\prime}, w^{\prime}\right) & \text { Velocity disturbance vector } \\ V_{g} & \text { Speed of wave propagation } \\ x, y, z & \text { Streamwise, spanwise and upwash directions (respectively) } \\ \boldsymbol{x} & \text { Observer position } \\ \boldsymbol{y} & \text { Source position } \\ \gamma & \text { Lean angle } \\ \Lambda & \text { Integral length scale } \\ \Phi_{w w} & \text { Upwash velocity spectrum } \\ \varphi & \text { Random phase } \\ \Theta^{2} & \text { Dispersion relation criterion }\end{array}$

*PhD Student, Computational Fluid Dynamics and Aeroacoustics Department.

${ }^{\dagger}$ Research Engineer, Computational Fluid Dynamics and Aeroacoustics Department. 


\section{Introduction}

Turbulent wakes generated by turbofan blades and interacting with the outlet guide vanes are known to be mainly contributing to broadband noise emission of aero-engines at approach conditions. The prediction and the reduction of broadband noise component due to turbulent sources interactions are then highly required by engine manufacturers. As turbofan rotor-stator full 3D stage is out of reach of today unsteady CFD computing capabilities, turbulent sources are generally studied through simplified configurations for which high-fidelity numerical simulations can be investigated, when analytical modelling is no longer possible. This was the motivation of two consecutive european projects PROBAND and FLOCON, respectively devoted to turbofan broadband noise prediction and reduction, by focusing on identified source mechanisms applied to generic cases such as rod-airfoil ${ }^{1}$ or turbulence-airfoil ${ }^{2}$ configurations. Passive treatments aiming at reducing turbulence interaction noise have been studied in FLOCON. A concept based on sinusoidal serrations (wavy edges) at the leading edge of a single airfoil has been investigated by ONERA. Turbulence-airfoil interaction mechanism is achieved using a turbulence grid located upstream of a NACA airfoil tested in ISVR (Institute of Sound and Vibration Research) anechoic open wind tunnel. High noise reductions have been obtained for all studied flow speeds ${ }^{3}$ and prediction methods have been investigated to try to assess these results.

Analytical approaches, such as the well-known Amiet model ${ }^{4,5}$ can be adopted to estimate the noise generated by turbulent flows impacting thin airfoils, but they are limited by the flat-plate assumptions. The development of numerical methods allowing more complex geometries and realistic flows is required. This is mandatory for example to study the serration effects on acoustics. Gust-airfoil interaction problem has been extensively investigated in numerous publications and more recently extended to turbulent source problem by means of different stochastic models to be coupled to the CAA. Lockard and Morris ${ }^{6,7}$ solved the gust-airfoil interaction case for NACA 0006 and NACA 0012 using a Navier-Stokes code. Scott ${ }^{8}$ provided benchmark solutions using the linearized Euler solver GUST3D for a linear vortical gust impinging on a Joukowski airfoil. Golubev et al. ${ }^{9-11}$ performed a vast study on the gust-airfoil interaction, taking interest on high frequencies and high amplitudes effects. Hixon et al. ${ }^{12-14}$ also worked on this problem using the NASA code BASS. Thus the gust-airfoil problem was numerically solved and recently extended to a three-dimensional annular cascade. Broadband calculations using turbulence stochastic models have been performed by Ewert ${ }^{15}$ for slat noise predictions. The generation of the turbulent field is obtained by filtering white noise. Dieste and Gabard ${ }^{16}$ also use this kind of stochastic model to simulate the turbulent wake / flat plate interaction. Salem-Said ${ }^{17}$ interests in the interaction between a homogeneous turbulence with a flat plate cascade using LES and a Fourier-modes decomposition of a prescribed kinetic energy spectrum to synthesize the turbulent inflow.

In FLOCON project, two different numerical methods have been proposed by ONERA to compute turbulence-airfoil interaction noise. Each method is aiming to simulate baseline and serrated airfoil cases and to be compared to the experimental results. The first method, developed by CERFACS is based on a RANS-LES chaining. ${ }^{18}$ The second method, described in the present paper, is based on a CAA code solving the nonlinear Euler equations. In both methods the upstream turbulence is synthesized from a stochastic model and injected into the computational domain through an adapted boundary condition. The CAA methodology and computational results are discussed in the paper.

\section{Method description}

\section{II.A. CAA solver and boundary conditions}

The current calculations are performed with the ONERA code sAbrinA.v0. ${ }^{19}$ It solves the full Euler equations in the time domain, and applying a perturbation form that consists in a splitting of the conservative variables into a mean flow and a fluctuating field. These equations are cast in generalized curvilinear coordinates to simulate flows around complex bodies. Such solving is classically conducted with the help of low-dissipative high-order finite differences $\left(6^{\text {th }}\right.$ order spatial derivatives and $10^{\text {th }}$ order filters), and a $3^{\text {rd }}$ order Runge-Kutta (RK3) time marching scheme. The code features multi-block structured grids and is parallelized using the MPI library.

To perform rotor-stator interaction CAA calculations, efficient numerical boundary conditions are required to allow hydrodynamic perturbations to be imposed at the inflow boundary and both hydrodynamic and acoustic outgoing waves to leave the domain without reflections. For this purpose, Tam and al. ${ }^{20-22}$ 
derived boundary conditions from the asymptotic solutions of the linearized Euler equations. The outflow boundary condition is written:

$$
\begin{aligned}
& \frac{\partial \rho^{\prime}}{\partial t}+\overline{\boldsymbol{u}} \cdot \nabla \rho^{\prime}=\frac{1}{a_{0}^{2}}\left(\frac{\partial \rho^{\prime}}{\partial t}+\overline{\boldsymbol{u}} \cdot \nabla p^{\prime}\right) \\
& \frac{\partial \boldsymbol{u}^{\prime}}{\partial t}+\overline{\boldsymbol{u}} \cdot \nabla \boldsymbol{u}^{\prime}=\frac{-1}{\bar{\rho}} \nabla p^{\prime} \\
& \frac{1}{V_{g}} \frac{\partial p^{\prime}}{\partial t}+\frac{\partial p^{\prime}}{\partial r}+\frac{p^{\prime}}{r}=0
\end{aligned}
$$

where $V_{g}=\overline{\mathbf{u}} . \mathbf{e}_{\mathbf{r}}+\sqrt{a_{0}^{2}-\left(\overline{\mathbf{u}} \cdot \mathbf{e}_{\boldsymbol{\theta}}\right)^{2}-\left(\overline{\mathbf{u}} . \mathbf{e}_{\boldsymbol{\phi}}\right)^{2}}$ is the speed of wave propagation in spherical coordinates. This condition was tested on basic cases and was found to be very efficient without the need of using stretched cells near the outflow boundaries. The incoming perturbations are injected in the computational domain through the inflow boundary using Tam's inflow condition:

$$
\frac{1}{V_{g}} \frac{\partial}{\partial t}+\frac{\partial}{\partial r}+\frac{1}{r}\left(\begin{array}{c}
\rho^{\prime} \\
\boldsymbol{u}^{\prime} \\
p^{\prime}
\end{array}\right)=\frac{1}{V_{g}} \frac{\partial}{\partial t}+\frac{\partial}{\partial r}+\frac{1}{r}\left(\begin{array}{c}
\rho_{i}^{\prime} \\
\boldsymbol{u}_{i}^{\prime} \\
p_{i}^{\prime}
\end{array}\right)
$$

where the subscript " $\mathrm{i}$ " denotes the incoming perturbation variables. This boundary condition permits simultaneously the injection of the incoming perturbations and the exit of outgoing acoustics waves. Tam ${ }^{22}$ argues that an improvement in the numerical accuracy can be found by using, if it is known, the exact expression of the derivatives in the right side of Eq. (2) instead of letting them be calculated by the numerical scheme. The sAbrinA.v0 solver uses a range of ghost-point rows generated automatically around the physical domains to perform the MPI exchanges required to ensure the continuity between the split domains. These ghost-points are also used for boundary conditions purposes. Tam's boundary conditions are calculated in these points only, and the spatial derivatives needed in the boundary conditions are calculated using standard uncentered finite difference schemes.

Tam's boundary conditions are generally written in spherical coordinates, and a point in the computational domain is judiciously chosen to be the radiation centre. However, for airfoil calculations over a long span with periodicity conditions in the spanwise direction, a more suited cylindrical formulation can be adopted. Then the radiation centre is translated along the span and the boundary conditions are treated as a succession of plans in the spanwise direction. Figure 1 represents a snapshot of the pressure fluctuation for a 3D gust-airfoil test case using the spherical formulation of the boundary conditions (left) and the cylindrical one (right). This case was only designed to highlight the benefits of the cylindrical formulation but not to perform an accurate calculation. A coarse mesh therefore has been used to permit a fast computation. In figure 1 (left), one can observe that for the slices far from the mid-span plane the wavefronts are deformed, whereas in figure 1 (right), the patterns are perfectly reproduced along the span (as expected for this case).
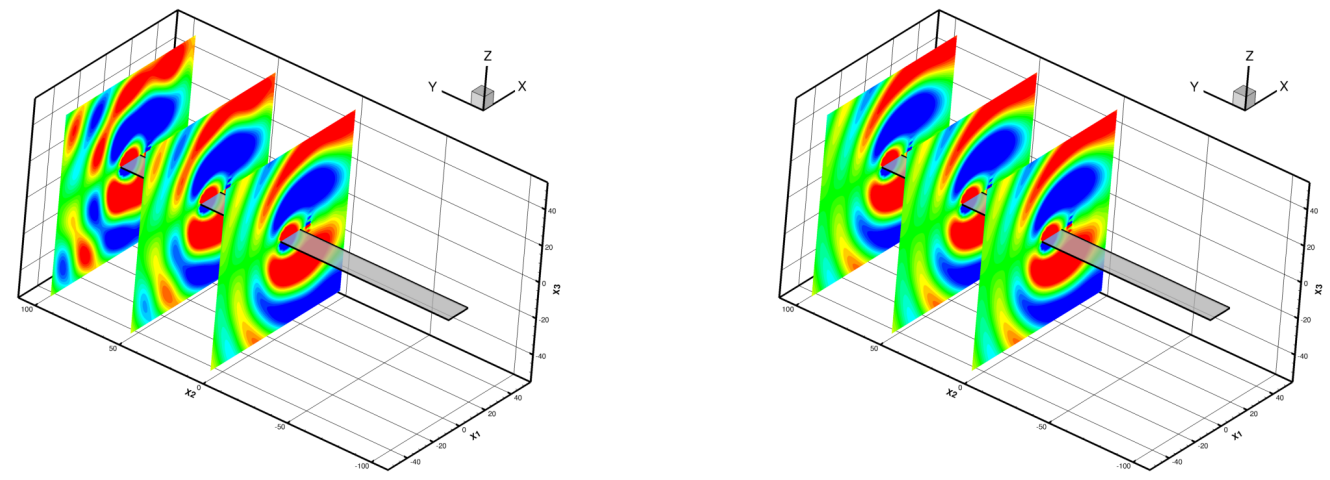

Figure 1. Pressure fluctuation snapshots of a gust-airfoil test case: Tam's boundary conditions using spherical formulation (left) or cylindrical formulation (right). 


\section{II.B. Stochastic model of the prescribed turbulent field}

The stochastic model presented here is inspired from Kraichnan's theory. ${ }^{23}$ As done in ref. [17], it is based on a Fourier-modes decomposition of the incoming turbulent wake modeled as homogeneous isotropic turbulence (HIT) energy spectrum. In the present study, only the upwash velocity component (normal to the airfoil assimilated as a flat plate) is considered with a spatial distribution over streamwise and spanwise wavenumbers, as done in Amiet's theory. ${ }^{4,5}$ This restriction will be discussed in section III.C. The modes amplitudes are fitted by a Von Karman energy spectrum, defined by two parameters: the turbulence intensity, $T_{I}$, and the integral lengthscale, $\Lambda$. Following the approach of Casper and Farassat, ${ }^{24} 3 \mathrm{D}$ calculations are performed using a two-wavenumber spectrum $\Phi_{w w}\left(k_{x}, k_{y}\right)$ corresponding to the integration of the three-dimensional energy spectrum over the normal wavenumber $\left(k_{z}\right)$. In the same way, for $2 \mathrm{D}$ calculations, the spectrum is integrated over the spanwise wavenumber $\left(k_{y}\right)$ to obtain the one-wavenumber spectrum, $\Phi_{w w}\left(k_{x}\right)$ as used in ref. [16]. Thus, the incoming velocity field can be written as:

$$
\begin{aligned}
u^{\prime}(\boldsymbol{x}, t) & =v^{\prime}(\boldsymbol{x}, t)=0 \\
w^{\prime}(\boldsymbol{x}, t) & =\sum_{i=1}^{N} \sum_{j=-M}^{M} 2 \sqrt{\Phi_{w w}\left(k_{x, i}, k_{y, j}\right) \Delta k_{x} \Delta k_{y}} \cos \left(k_{x, i} x+k_{y, j} y-\omega_{i} t+\varphi_{i j}\right) \\
w^{\prime}(\boldsymbol{x}, t) & =\sum_{i=1}^{N} 2 \sqrt{\Phi_{w w}\left(k_{x, i}\right) \Delta k_{x}} \cos \left(k_{x, i} x-\omega_{i} t+\varphi_{i}\right)
\end{aligned}
$$

The unsteady disturbance field is assumed to be convected through a uniform mean flow $U_{0}$ in the $x$ direction (Taylor's frozen turbulence hypothesis), so that the angular frequency $\omega_{i}$ is related to the streamwise wavenumber by $\omega_{i}=U_{0} k_{x, i} \cdot \varphi_{i, j}$ is a random phase associated to the $(i, j)$ mode, chosen between 0 and $2 \pi$. When considering a realistic RANS mean flow in the CAA, the convection speed of the frozen turbulence in set equal to the undisturbed upstream flow. The synthetic turbulent field so obtained is divergence-free, which prevents from creating any additional sound sources.

\section{II.C. Far-field radiation}

Although the acoustic response of the airfoil can be directly provided by the Euler computation if the domain is large enough to reach the far-field, the radiation can be practically obtained by integral methods (Kirchhoff or Ffowcs-Williams and Hawkings porous formulations) allowing us to limit the size of the mesh, particularly for $3 \mathrm{D}$ cases with complex geometries. Turbulence-airfoil interaction mechanism is known to create dipole sources distributed over the airfoil surface. Thus, in the following 3D computations, far-field radiation can be calculated using a standard (solid surface) FWH method, restricted to the loading noise term as in Curle's theory. A frequency domain approach is adopted here, which can be written:

$$
\hat{p}(\boldsymbol{x}, \omega)=\int_{S} \hat{p}(\boldsymbol{y}, \omega) n_{i} \cdot \frac{\partial \hat{G}(\boldsymbol{x}, \omega \mid \boldsymbol{y})}{\partial y_{i}} d S
$$

where $x$ is the observation position and $y$ is the source position. $\hat{G}(\boldsymbol{x}, \omega \mid \boldsymbol{y})$ is the free field Green's function with uniform flow convection, and $\hat{p}(\boldsymbol{y}, \omega)$ are the Fourier transformed wall pressure fluctuations provided by sAbrinA.v0. In the following work, these integral calculations are performed using the parallelized ONERA solver MIA developed by G. Reboul.

\section{Validation cases}

\section{III.A. Single harmonic gust interacting with a 2D flat-plate}

The case of a single gust interacting with a flat plate with no thickness is of particular interest, because an exact solution derived by Amiet ${ }^{4,5}$ is available. It can be adapted to $2 \mathrm{D}$ problems as done by Reboul. ${ }^{25}$ Such a 2D case is useful to highlight specific behaviors such as the non-compactness effects on the acoustic response for high frequencies. The single gust is defined by a streamwise wavenumber $k_{x}$ (nondimensionalized by half the chord), and the amplitude is chosen to satisfy the linearity assumptions (Golubev ${ }^{9}$ has shown that for high amplitudes gusts, non-linear effects may give rise to harmonics in the acoustic response). The 
incident perturbation field considered is of the form:

$$
\begin{aligned}
u^{\prime}(\boldsymbol{x}, t) & =0 \\
w^{\prime}(\boldsymbol{x}, t) & =\varepsilon U_{0} \cos \left(\frac{2 k_{x}}{c}\left(x-U_{0} t\right)\right)
\end{aligned}
$$

where $c=1.0 \mathrm{~m}$ is the chord of the flat plate, $\varepsilon=0.02$ is the gust intensity relative to the mean flow $U_{0}$ with a Mach number set to $M=0.5$. Three grids have been designed for these validation cases. The grids are clustered at the leading and trailing edges in order to resolve the abrupt transition effects and to well capture the pressure peak at the leading edge. The grids extend until at least 6 chords around the airfoil ensuring at least 10 points per wavelength respectively for the reduced wavenumbers $k_{x}=1.0,3.0,5.0,10.0$.

One should know that when performing the calculation for the wavenumber $k_{x}=3.0$ using the dedicated grid, important discrepancies appeared on the directivities. The same computation was then performed using the finest of the three grids and the results are by far in better agreement with Amiet's theory. This tends to show that a specific refining effort is needed for this particular wavenumber (it has to be noted that the reduced value $k_{x}=3.0$ corresponds to a wavelength which is really close to the chord of the flat plate). In order to speed up the transient state induced at the beginning of the calculations (before reaching the periodic state), the fluctuating field given by Eq. (6) is initialized over the entire domain.

Figure 2 shows snapshots of the upwash velocity (left) and pressure (right) fluctuations for the $k_{x}=1.0$ (top) and $k_{x}=5.0$ (bottom) wavenumbers. As expected for gust-airfoil interaction mechanism the radiated field is dipolar and, for this particular case of a flat plate, symmetric. The visible change in the pattern of the radiated field between $k_{x}=1.0$ and $k_{x}=5.0$ is due to the loss of compactness at high frequency. Figure 3 shows the RMS pressure on the suction side of the plate and figure 4 presents the directivity for an observer distance of 4 chords around the center of the airfoil. As the acoustic responses are symmetrical, only the upper half is represented. The computational results are in good agreement with Amiet's solution and fairly well predicts the growing number of lobes due to the loss of compactness as the frequency increases. The discrepancies observed for the highest wavenumber might be lowered too if using more refined mesh.
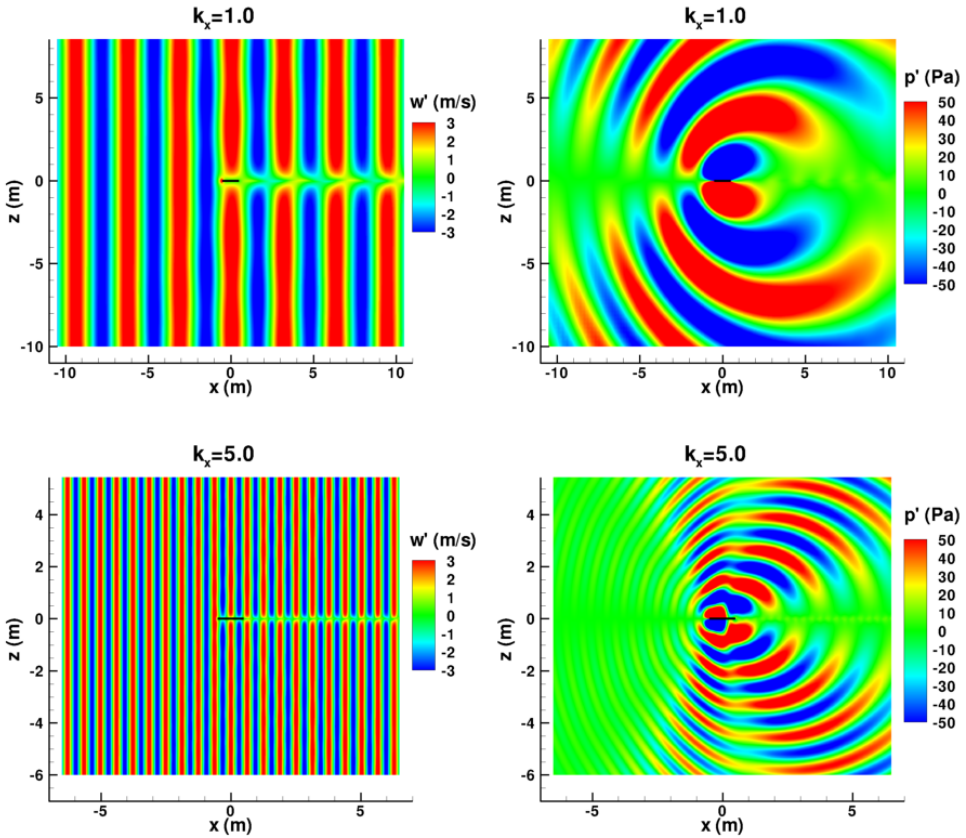

Figure 2. Upwash velocity component (left) and fluctuating pressure field (right). 


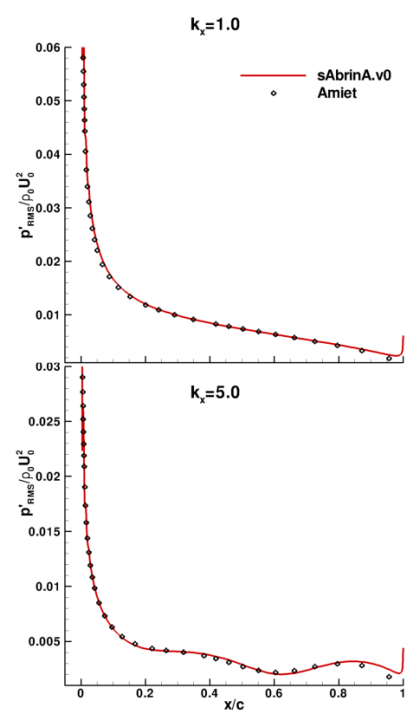

Figure 3. RMS wall pressure.
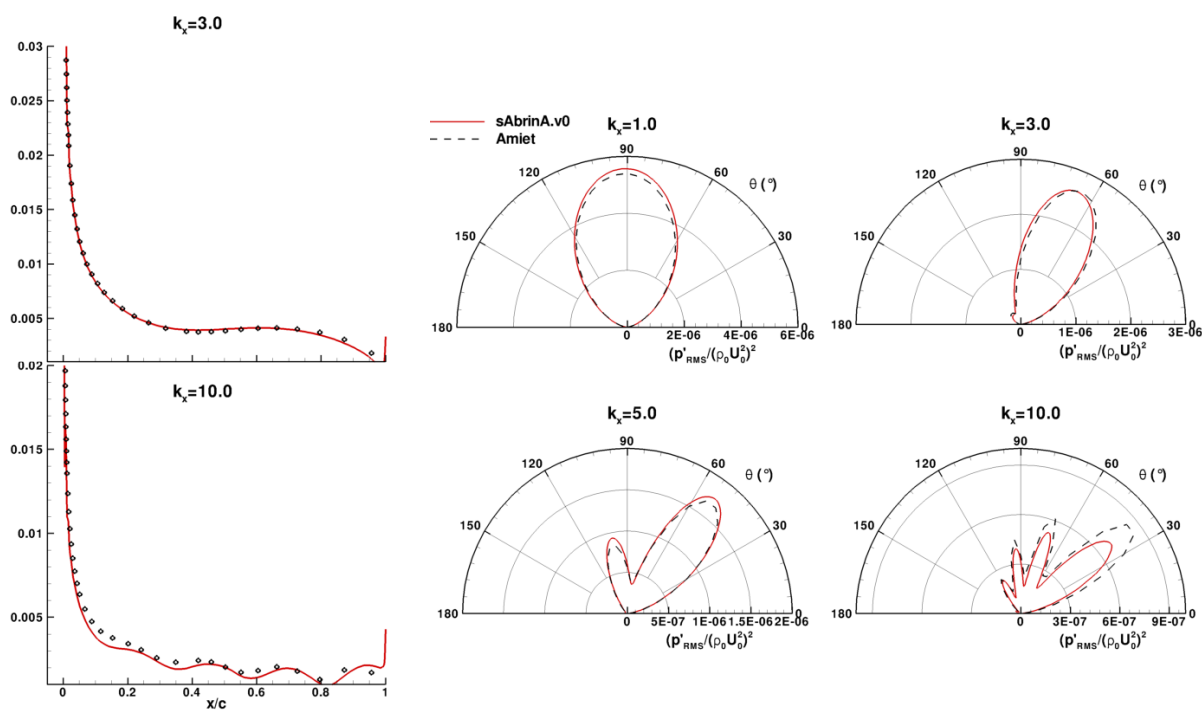

Figure 4. Directivities at 4 chords.

\section{III.B. HIT interacting with a 2D flat plate}

The previous 2D flat plate cases with single gust are now extended to the computation of a synthetic turbulence described by Eq. (4). The finest mesh is considered and the axial mean flow Mach number is set to $M=0.5$. Modes are injected between $k_{\min }=1.0$ and $k_{\max }=10.0$ with $\Delta k=0.2$. The $1 \mathrm{D}$ Von Karman spectrum is defined by $\Lambda=0.18 \mathrm{~m}$ and $T_{I}=4.56 .10^{-3}$.

Snapshots of velocity and pressure disturbances computed by CAA are plotted in figure 5 , still showing the symmetric dipole pattern but with a broadband nature. Figure 6 presents the power spectral density (PSD) directly assessed from sAbrinA.v0 for an observer located at 4 chords above the centre of the airfoil and compared to Amiet's solution. Note that present Amiet's solution is strictly exact including the nearfield term contribution (no far-field assumptions are used). A very good agreement is found between the numerical and the analytical predictions.
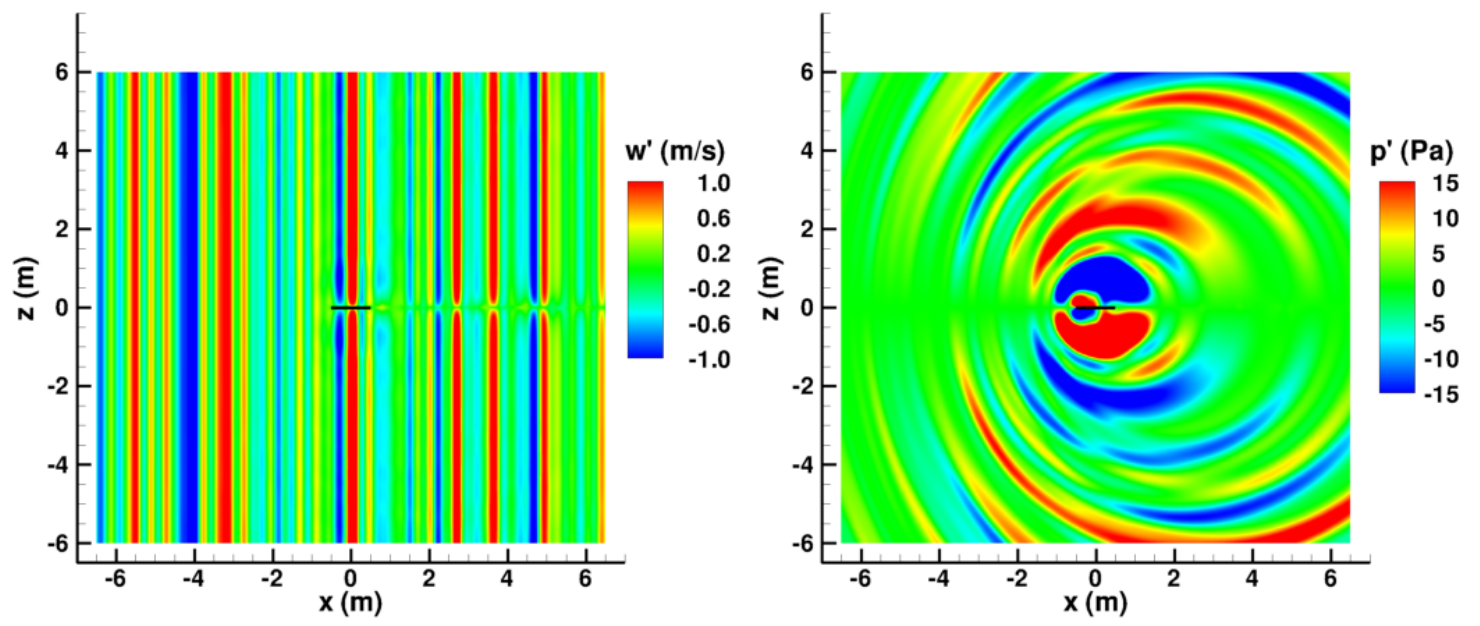

Figure 5. Upwash velocity component (left) and fluctuating pressure field (right). 


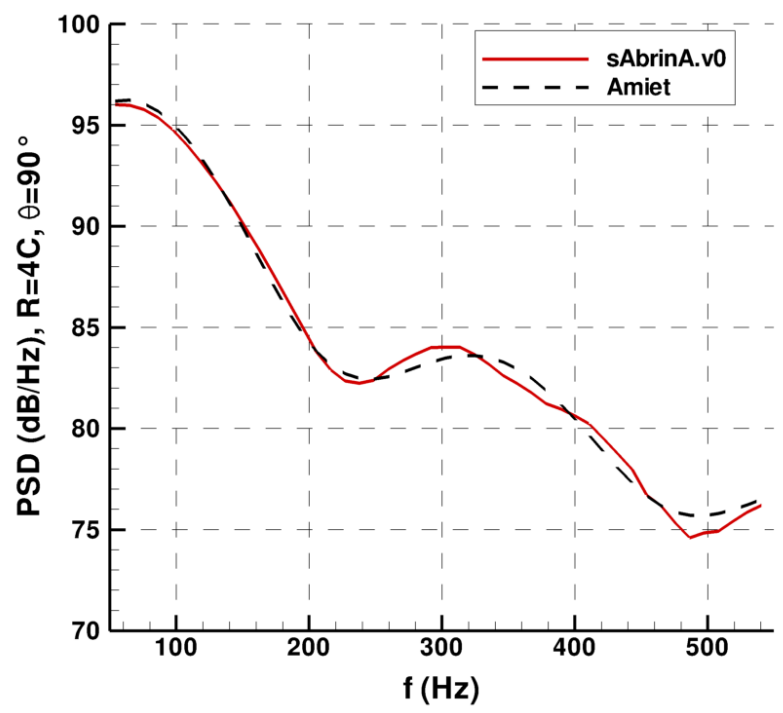

Figure 6. PSD at 4 chords and $90^{\circ}$.

\section{III.C. 3D flat plate computation and coupling with FWH integral method}

The CAA computations are extended in 3D and validated again on a flat plate case. The acoustic predictions issued from the coupling with the FWH integral described in section II.C are presented and discussed. In order to get a reasonable CAA grid size, 3D computations are practically performed by restricting the full span $L_{\text {span }}$ to a spanwise strip with length $L_{\text {sim }}$ and imposing periodicty conditions at each side. This implies to choose wavelengths of spanwise wavenumbers $k_{y}$ to be multiples of the simulated span $\left(k_{y, n}=n 2 \pi / L_{\text {sim }}\right)$ so that the two-wavenumber spectrum is discretized using a spanwise wavenumber step $\Delta k_{y}=2 \pi / L_{\text {sim }}$. It appears that the suited spanwise extent required to ensure a significant part of the spectrum related to the most energetic values of $k_{y}$ is still demanding heavy mesh size (about 100 Million points), involving quite expensive calculations. As done in ref. [24], a simplification is proposed to avoid this problem.

Amiet argued that for a far-field observer in the mid-span plane of an infinite flat-plate (practically, when the span to chord ratio is greater or equal to 3$)$, the parallel gusts $\left(k_{y}=0\right)$ are mainly contributing to the radiated noise. Indeed it can be shown that the contribution of cut-on oblique gusts corresponding to $k_{y}<k_{x} M / \sqrt{1-M^{2}}$ cancel out in the mid-span plane for a far-field observer located in the mid-span plane. This effect is highlighted in figure 7, in which Amiet calculations are performed for two observers located respectively at 8 chords and 65 chords above a flate plate (with a span to chord ration of 3 ), by using the complete spectrum $\Phi_{w w}\left(k_{x}, k_{y}\right)$ or the zero-spanwise wavenumber spectrum $\Phi_{w w}\left(k_{x}, 0\right)$. As for the 2D case, the 3D Amiet solutions are obtained without far-field approximations. They are derived from a numerical integration of the response of the flat-plate using analytical aerodynamic functions. ${ }^{25}$ Thus an exact acoustic response with full compactness effects can be assessed. At 8 chords (Fig. 7, left) discrepancies are visible between the two calculations with and without oblique gusts contribution because the observer is not far enough from the airfoil, but at 65 chords (Fig. 7, right) the two results become identical.

Taking advantage from these conditions, only the parallel gusts can be considered in Eq. (3) when injected in the CAA (if the span to chord ratio assumptions are satisfied), which allows us to use a very limited spanwise extent. However, when using the zero-spanwise wavenumber spectrum $\Phi_{w w}\left(k_{x}, 0\right)$, explicit values of $\Delta k_{y}$ are no more defined. In Amiet's theory, 3D non-compact and 2D compact formulations, respectively related to the overall spectrum $\Phi_{w w}\left(k_{x}, k_{y}\right)$ and to the parallel gusts spectrum $\Phi_{w w}\left(k_{x}, 0\right)$, give rise to a $2 \pi / L_{\text {span }}$ factor when calculating the far-field PSD. This factor has to be included in the CAA in order to get the correct aerodynamic response of the full span airfoil. This is done by setting $\Delta k_{y}=2 \pi / L_{\text {span }}$.

To check this scaling factor, we consider a flat-plate with $c=0.15 \mathrm{~m}$ and $L_{\text {span }}=0.45 \mathrm{~m}$, and a uniform mean flow $U_{0}=60 \mathrm{~m} / \mathrm{s}$. The Von Karman spectrum is defined with $\Lambda=6 \mathrm{~mm}$ and $T_{I}=0.025$. These parameters are similar to the FLOCON application case presented in section IV. The incoming 

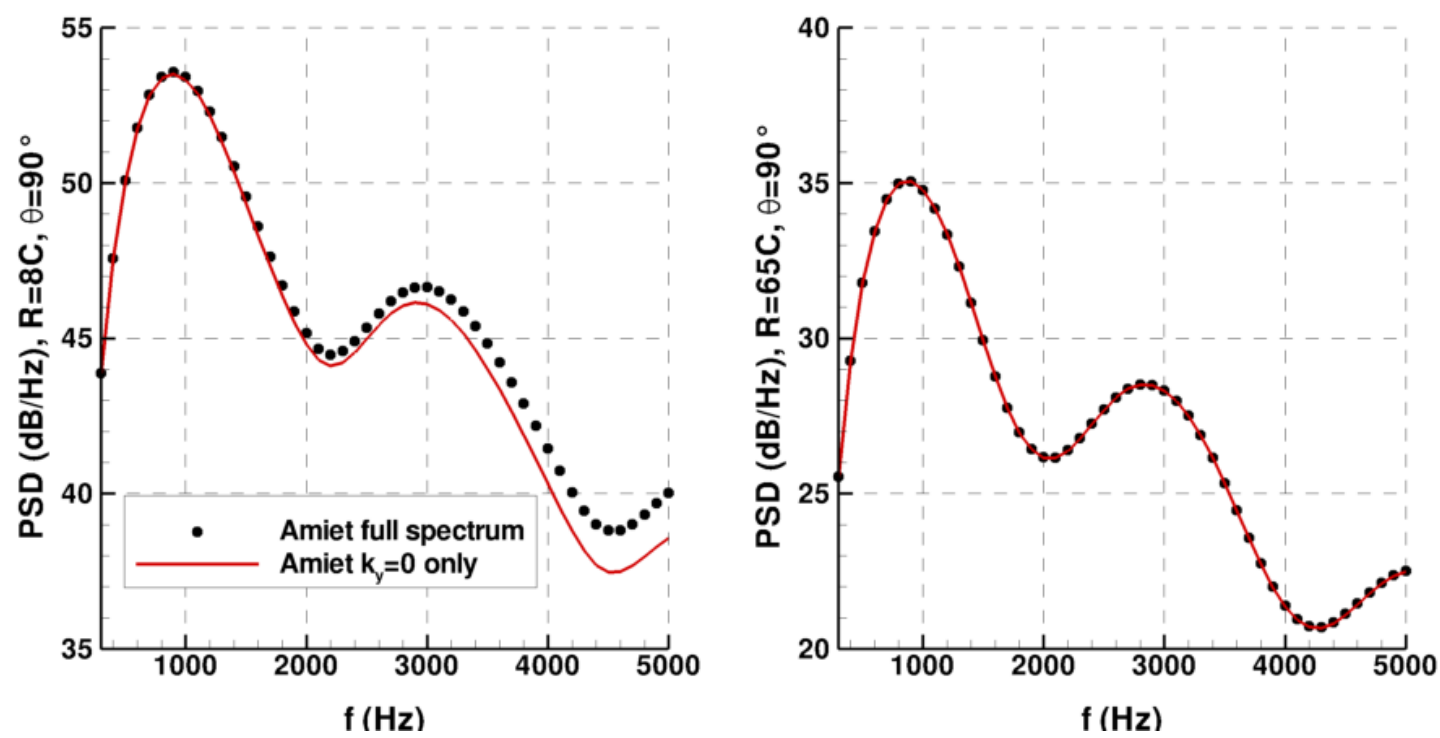

Figure 7. PSD issued from Amiet calculations at 8 chords and 65 chords above a flate plate.

synthetic turbulence defined by Eq. (3) is restricted to parallel gusts with wavenumbers corresponding to a maximum frequency $f_{\max }=5000 \mathrm{~Hz}$ and a frequency spacing $\Delta f=100 \mathrm{~Hz}$. The CAA strip is set equal to $L_{s i m}=10 \mathrm{~mm}$. Note that in order to take into account for compactness effects, the input data will be duplicated in the spanwise direction over the full span $L_{\text {span }}$ before calculating the FWH integral given by Eq. (5).

A snapshot of the fluctuating pressure issued from the direct CAA computation in the mid-span plane is shown in figure 8. A comparison of the RMS wall pressure distributions issued from CAA and Amiet-based response is plotted in figure 9 showing a perfect agreement. The possibility of using the direct acoustic pressure field to estimate the far-field PSD with suited scaling factors has been investigated. But here the whole computational domain is in the near-field, and the use of a spreading law correction factor to extrapolate the near-field solution up to the far-field is not relevant because the level correction is linked to the frequency. The results for a $90^{\circ}$ observer point located in the mid-span plane at $1.2 \mathrm{~m}$ are compared in figure 10. The computed PSD provided by CAA-FWH is close to the Amiet solutions obtained with and without including the oblique gusts. The oscillations observed in the numerical results might be explained by the pressure peak near the trailing edge (Fig. 9) which is not present in the analytical solution. The presence of this peak is explained by the violation of the Kutta condition at the trailing edge. The numerical spectrum should get smoothed if the trailing edge region in the FWH integration is removed. Nevertheless the numerical solution is quite satisfactory.

In order to assess the flat plate response to oblique gusts before performing heavy CAA computations, a semi-analytical method consisting in calculating the unsteady pressure jump on the flat plate and then using it as an input to the FWH solver MIA has been investigated. The pressure jump on the flat plate is calculated using Amiet's aerodynamic function $g\left(x, k_{x}, k_{y}\right)$ as follows, in the time domain:

$$
\Delta p(x, y, t)=2 \pi \rho_{0} U_{0}\left(\sum_{i=1}^{N} \sum_{j=-M}^{M} 2 \sqrt{\Phi_{w w}\left(k_{x, i}, k_{y, j}\right) \Delta k_{x} \Delta k_{y}} g\left(x, k_{x, i}, k_{y, j}\right) e^{i\left(k_{x, i} U_{0} t-k_{y, j} y+\varphi_{i j}\right)}\right)
$$

Or in the frequency domain:

$$
\Delta \hat{p}(x, y, \omega)=2 \pi \rho_{0} U_{0}\left(\sum_{i=1}^{N} \sum_{j=-M}^{M} 2 \sqrt{\Phi_{w w}\left(k_{x, i}, k_{y, j}\right) \Delta k_{x} \Delta k_{y}} g\left(x, k_{x, i}, k_{y, j}\right) e^{i\left(-k_{y, j} y+\varphi_{i j}\right)}\right)
$$

When using the time formulation (Eq. (7)), only the real part of the pressure jump so calculated is considered as an input for the integral method. The discretization of the flat plate for these semi analytical 


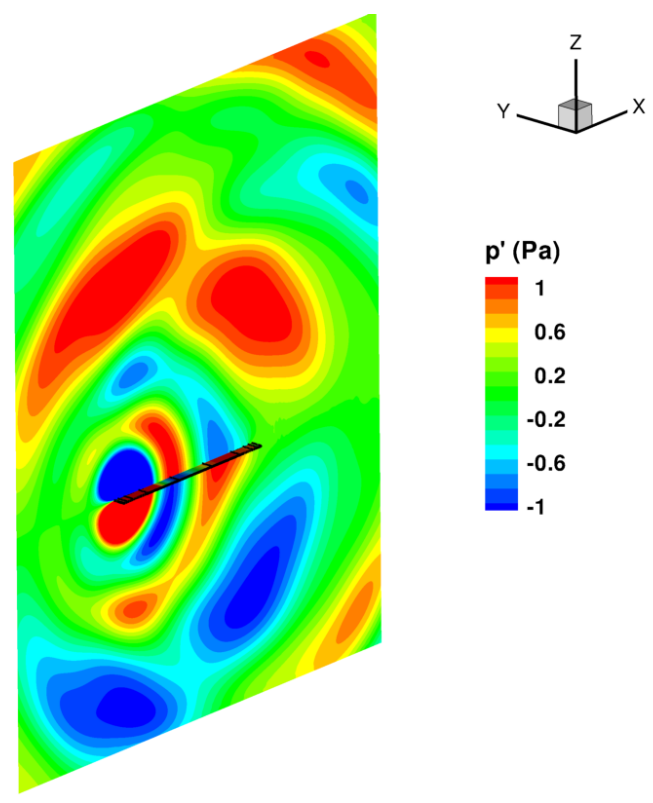

Figure 8. Snapshot of disturbance pressure field in the mid-span plane.

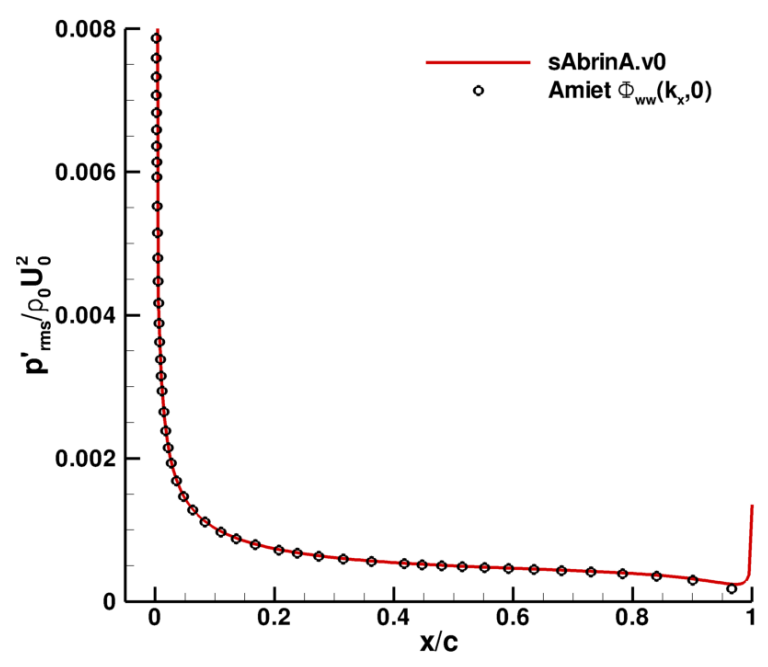

Figure 9. RMS wall pressure for the 3D flat plate.

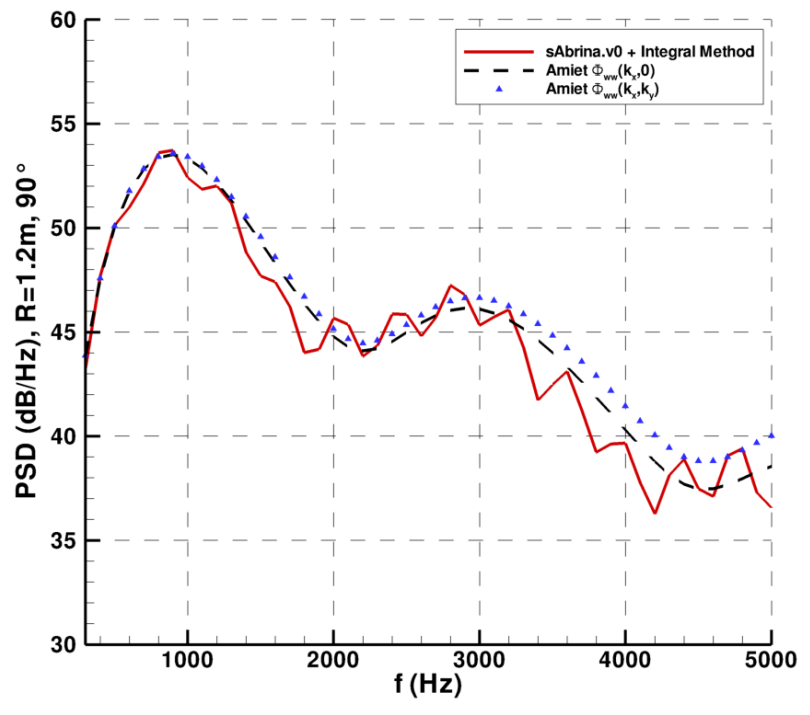

Figure 10. Predicted PSD at $R o b s=1.2 \mathrm{~m}$ and $90^{\circ}$.

computations is shown in figure 11. The RMS pressure distributions over the surface are plotted in figure 12 (right) and compared to a theoretical uniform distribution (Fig. 12, left). We can observe a quasi-uniform distribution in the spanwise direction (as expected), which makes this synthetic turbulent inflow modelled by Eq. (7) reliable in terms of statistical energy.

However, the far-field PSD issued from MIA shown in figure 13 (left) is found to be quite chaotic compared to Amiet's solution. This is due to cancellation effects between spanwise waves related to the same streamwise wavenumber (i.e., the same frequency). To reduce these statistical deviations, two averaging processes are suggested. The standard one is to perform a quadratic averaging over several independent computations. The second one is to realize a single run with a smaller frequency spacing and then to smooth the spectrum by integrating the levels over consecutive frequency bands. Both methods are applied in figure 13 (right), using 10 computations for the first one, and using a 10-times smaller frequency spacing and integrating over 


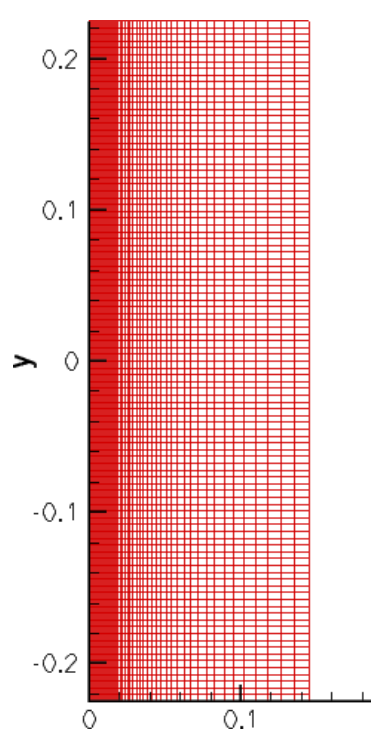

Figure 11. Flat plate mesh.
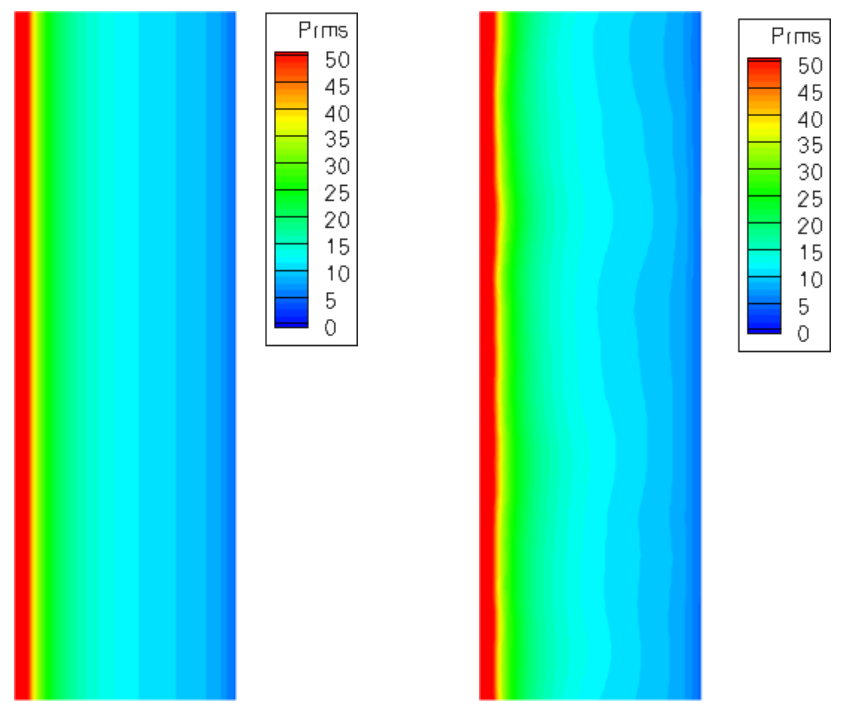

Figure 12. RMS surface pressure issued from theory (left) and computation (right).

10 bands for the second. The predictions are highly improved by the averaging.
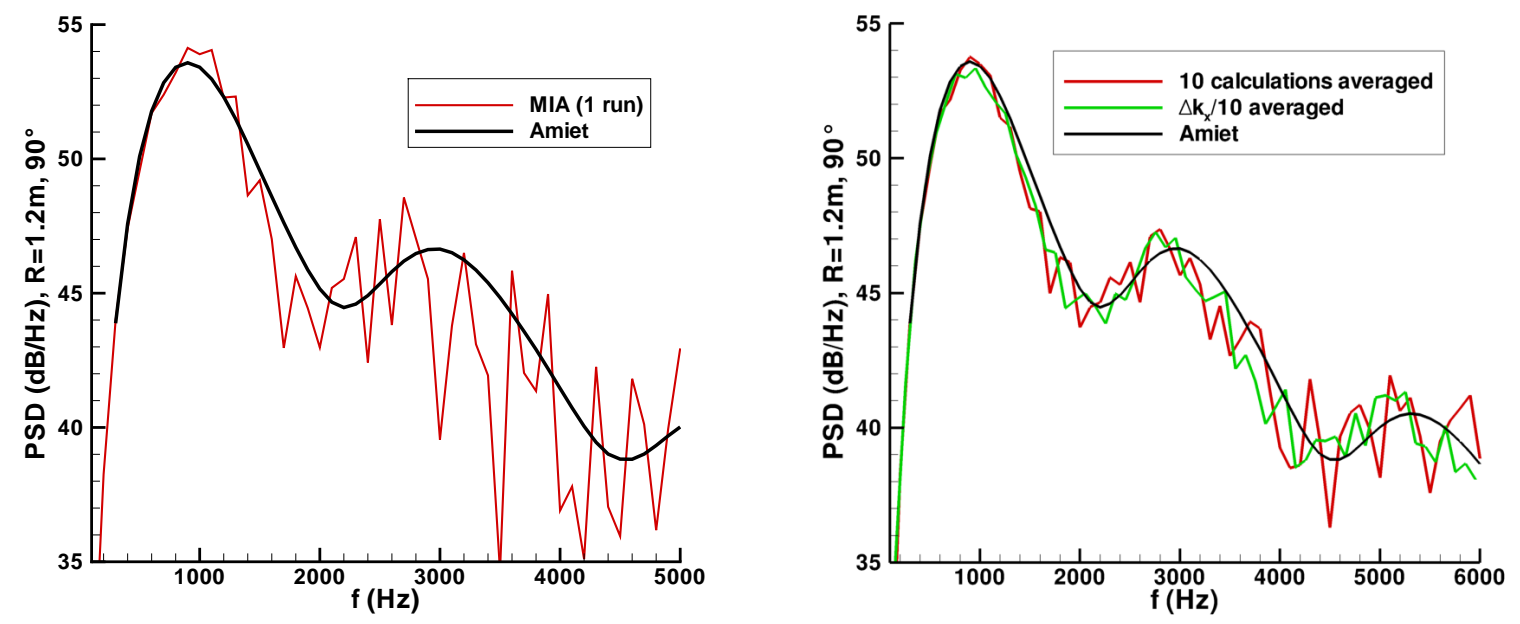

Figure 13. Predicted PSD at $90^{\circ}$ and $R_{o b s}=1.2 m$ using oblique gusts: without averaging (left) and with averaging over 10 calculations or over 10 frequency bands for 1 calculation with $\Delta f / 10$ (right).

The second approach seems to work at least as well as the classical one and has the advantage of having to perform only one computation. Thus instead of loosing computation time in reaching the converged periodic state for each run, the simulation time required to satisfy the desired frequency resolution response has just to be longer for a simple run.

First attempts of injecting a turbulent perturbation in a CAA computation using the complete spectrum $\Phi_{w w}\left(k_{x}, k_{y}\right)$ underlined another difficulty. When dicretizing the spectrum over streamwise and spanwise wavenumbers, the number of modes to sum in order to generate the incoming perturbation in Eq. (3) become very important, and then the computation of the right side in Eq. (2) appears to be a major CPU time consumer, leading to an important slowdown of the computation. This slowdown added to the requirement of a longer simulation duration are still challenging and a specific effort has to be done to improve the efficiency of this source term generation in Tam's inflow condition. When looking at the incoming wake 
formulation in Eq. (3), it appears that the cosine can be split to separate the spatial component (depending on $x, y$ ) from the temporal one (depending only on $t$ ). Thus the spatial part can be calculated at the beginning of the computation and only the temporal part have to be calculated at each iteration. This splitting prevents from calculating the double summation at each iteration and allows to perform only the summation over the frequencies. In another hand it requires a huge increase of memory size to store the spatial component during the whole computation.

\section{Application to FLOCON configurations}

The methodology presented in section II is now applied to try to assess the acoustic performance of a leading edge passive treatment studied in the framework of the European project FLOCON. ${ }^{3}$ It is applied to the baseline configuration (NACA 651210 airfoil described in figure 14, left) and to a treated airfoil with leading edge serrations designed by ONERA (Fig. 14, right). The airfoils have a $0.15 \mathrm{~m}$ chord and a $0.45 \mathrm{~m}$ span. The serrations are sinusoidal waves with an amplitude $h=10 \mathrm{~mm}$ and a wavelength $\lambda_{s}=10 \mathrm{~mm}$. The tests performed in ISVR anechoic wind tunnel on isolated airfoil and tandem airfoils configurations ${ }^{26}$ have shown significant broadband noise reductions on a wide frequency range for all studied flows. The mean flow is assumed to be uniform $\left(U_{0}=60 \mathrm{~m} / \mathrm{s}\right)$. As in section III.C, only the parallel gusts are considered, which allows the use of a CAA domain restricted to $10 \mathrm{~mm}$ in the spanwise direction (as done in the 3D flat plate case in section III.C). The incident turbulent velocity field injected in the computational domain is the same than in section III.C, and the parameters of the Von Karman spectrum $\left(\Lambda=6 \mathrm{~mm}\right.$ and $\left.T_{I}=0.025\right)$ are deduced from the measurements in ISVR test rig.
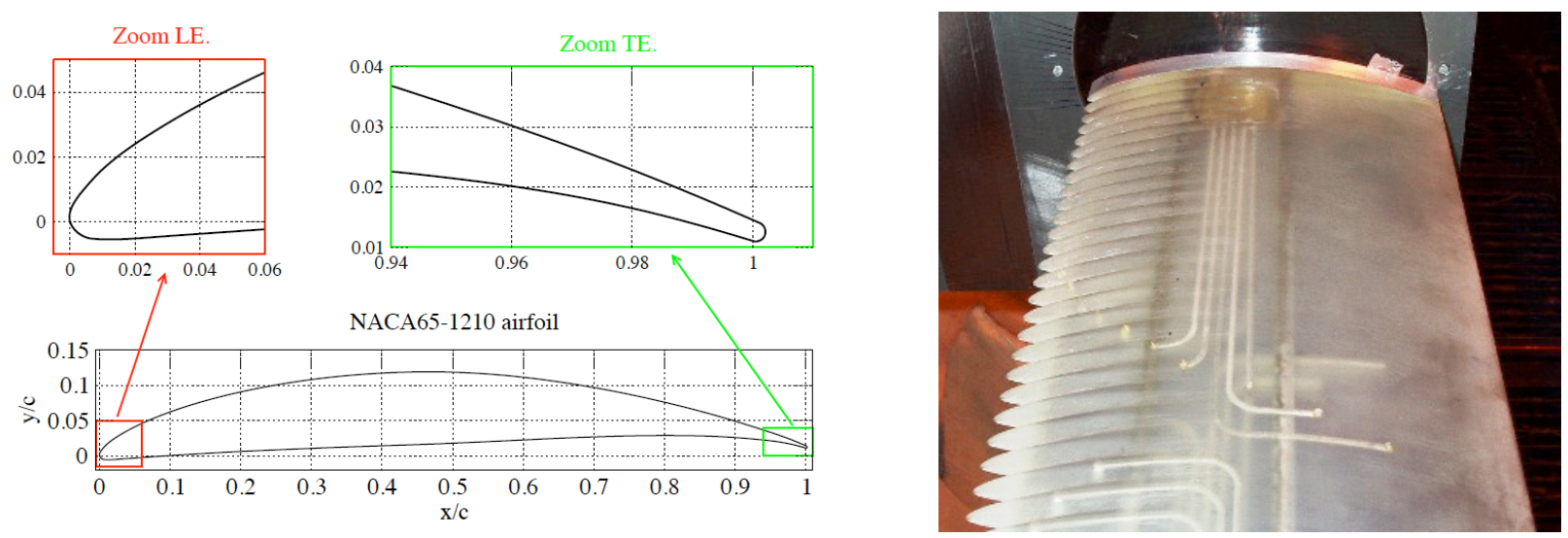

Figure 14. NACA651210 airfoil geometry (left) and ONERA serrated wing (right).

\section{IV.A. Baseline configuration}

The computational domain ( $1 / 45^{\text {th }}$ of the full span extent) consists in approximately 8.5 millions grid points and a CPU time of around 120 hours on 256 SGI Altix processors is required to get a fully converged solution. The grid is designed to support injected gusts up to $5 \mathrm{kHz}$, and the simulation duration (once convergence is achieved) has to be at least equal to $10 \mathrm{~ms}$ to ensure the frequency spacing to be equal to $100 \mathrm{~Hz}$. As for the flat plate case, the extracted unsteady data are duplicated in the spanwise direction to reach the actual $0.45 \mathrm{~m}$ span. The PSD computed by CAA+FWH for the baseline configuration and for an observation point at $90^{\circ}$ and $1.2 \mathrm{~m}$ over the airfoil (corresponding to a microphone position in ISVR test rig) is presented in figure 15. It is compared to the experiment and to Amiet solution.

Despite a noticeable deviation on the peak level for low frequencies behind $1 \mathrm{kHz}$, the agreement is quite satisfactory. The high levels on the measured low-frequency spectrum might be partially attributed to additional sources as discussed in ref. [26]. The numerical predictions are very close to the Amiet solution which is consistent with preliminary $2 \mathrm{D}$ computational results. As shown in ref. [3] for 2D computations, a better agreement should be obtained if convection effects (RANS mean flow solution) were taken into account in the CAA, since the presence of shear layers tends to increase the attenuation slope of the acoustic spectrum. The OASPL results are presented in figure 16 showing similar directivity patterns between CAA 
and Amiet solutions, and rather close to the experiment. The simulation reveals a roughly constant underestimation around $5 d B$ over all angles due to the level deviation on the low frequencies. A slight difference between CAA and Amiet directivity patterns are attributed to the non-symmetrical lifting airfoil which seems to increase the radiated noise in the front arc, and to decrease it in the rear arc.

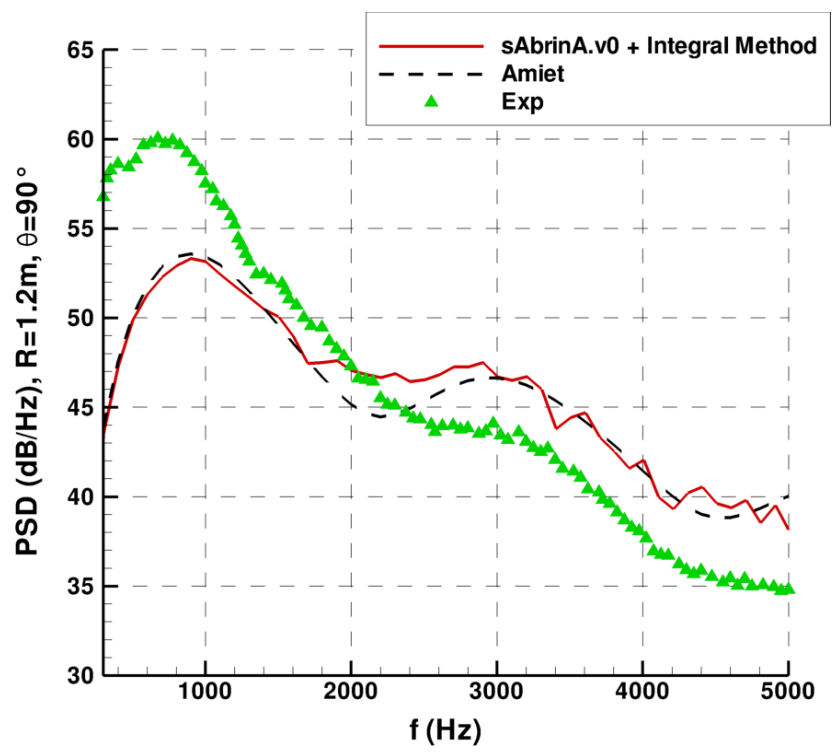

Figure 15. PSD at $R_{o b s}=1.2 \mathrm{~m}$ and $90^{\circ}$ for the baseline case.

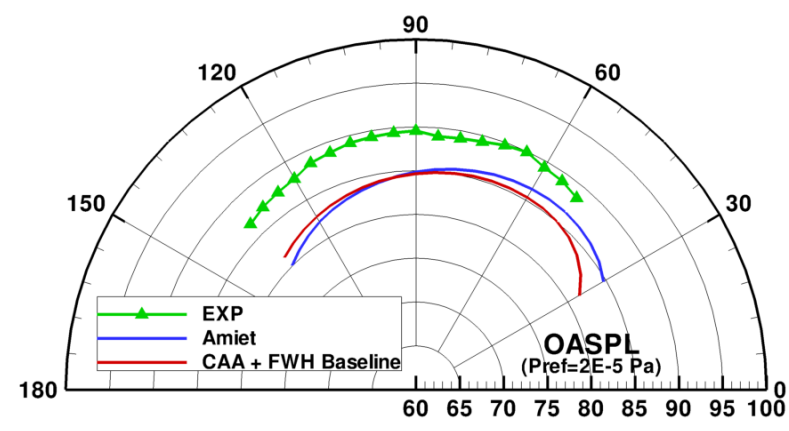

Figure 16. OASPL at $R_{o b s}=1.2 \mathrm{~m}$ for the baseline case.

\section{IV.B. Serrated airfoil response to parallel gusts}

The serrated airfoil configuration requires a finer discretization in the spanwise direction, leading to a mesh of about 13.3 millions points. The CPU time is around 300 hours on 256 processors. A partial view of the CAA grid is shown in figure 17 . The $10 \mathrm{~mm}$ spanwise extent is equal to the serration wavelength $\left(L_{s i m}=\lambda_{s}\right)$, so that periodicity conditions can be applied.

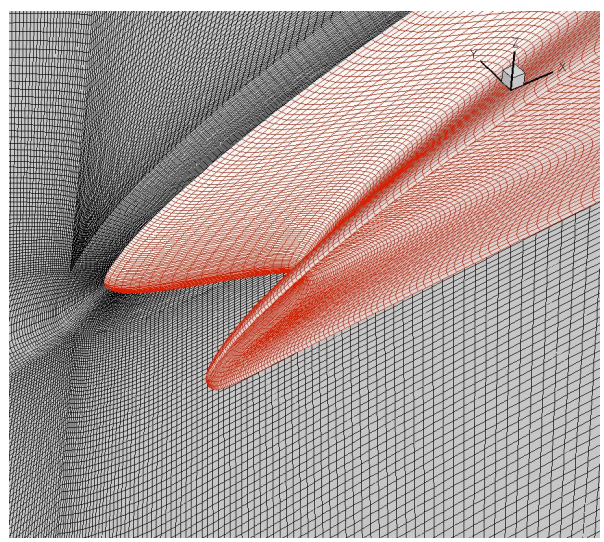

Figure 17. Partial view of the CAA mesh for the serrated wing.

A comparison between baseline and serrated cases in terms of RMS pressure fluctuation over the airfoil surface and along the chord are proposed in figures 18 and 19, respectively. The serration effect is clearly highlighted in figure 18, revealing significant reductions of the levels at the top and slopes of the wave. This is addressed more precisely in figure 19, showing that the pressure peak at the leading edge at the root of the serration is slightly amplified compared to the baseline configuration, whereas it is reduced by more than a half at the top and at mid-slope. Significant noise reductions are then expected from these observations. 

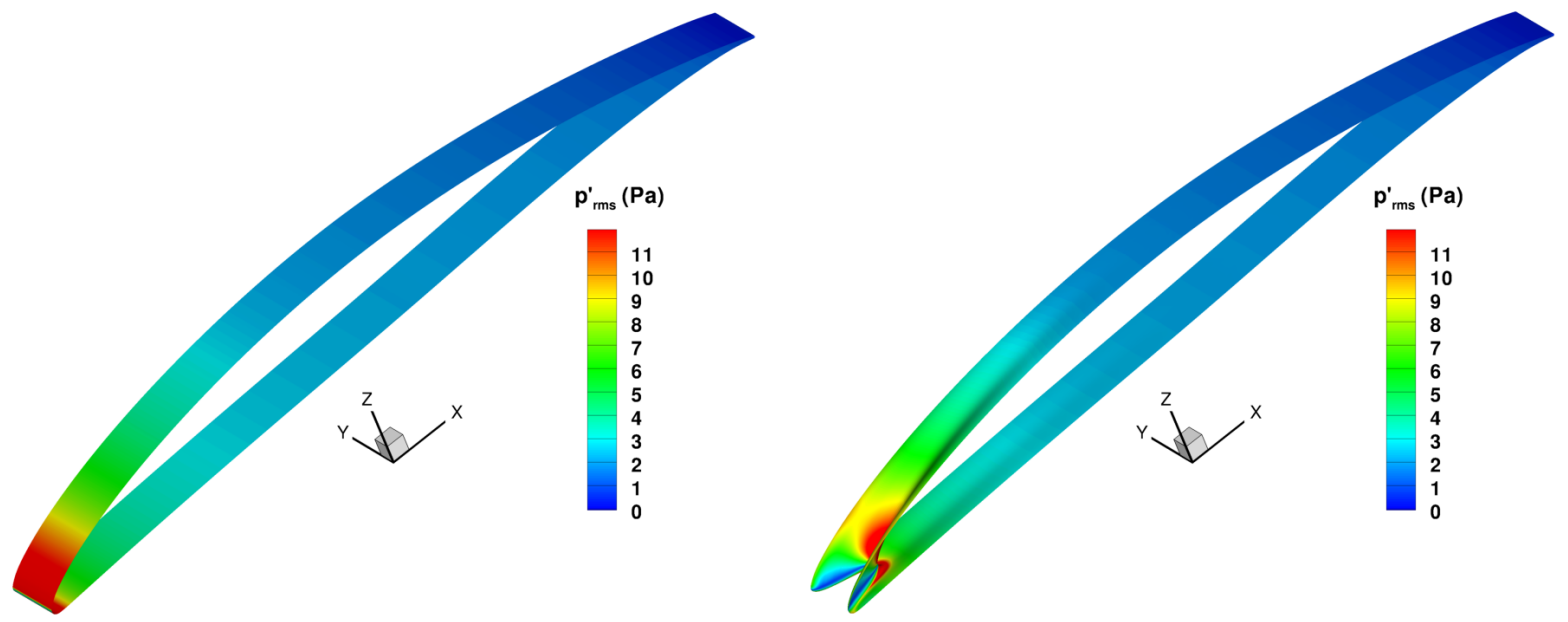

Figure 18. RMS surface pressure issued from CAA on baseline (left) and serrated (right) cases.
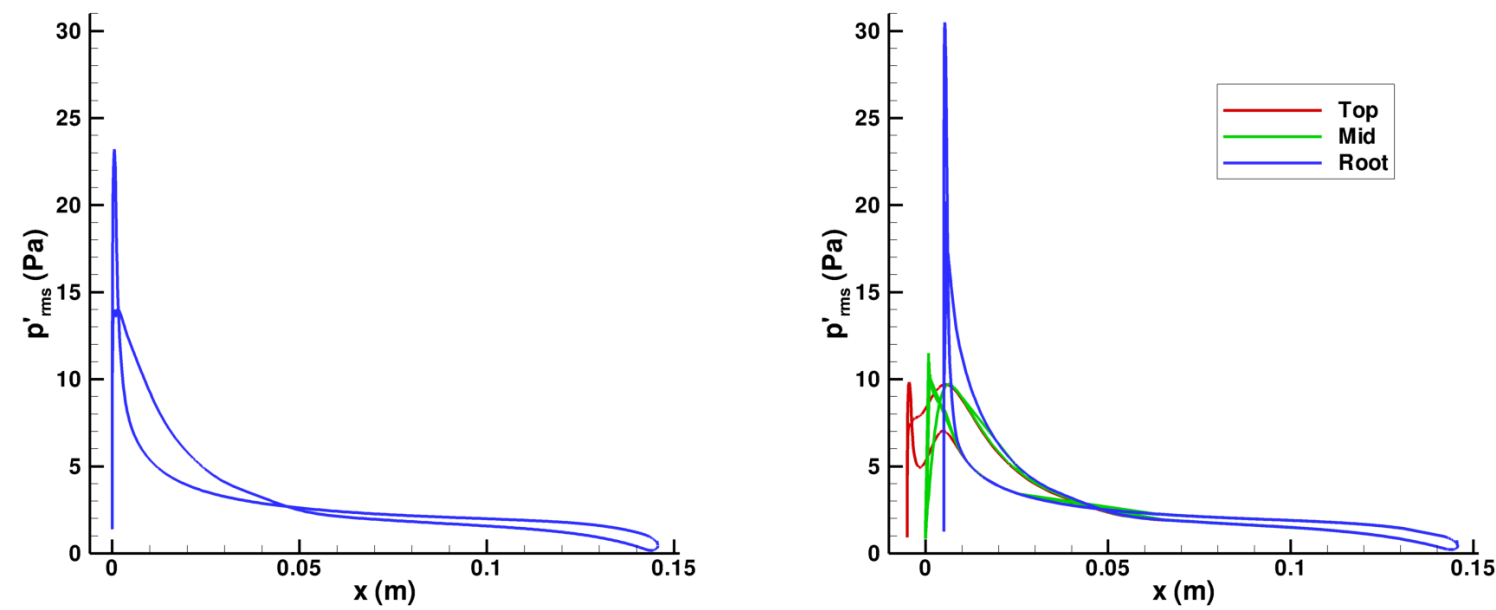

Figure 19. CAA chordwise RMS pressure profile on baseline (left) and serrated (right) cases.

Figure 20 shows a PSD comparison between the baseline and the serrated configurations issued from the experiments (left) and the simulations (right). Quite similar trends are visible between the measurements and the numerical predictions with very close level reductions up to $3.5 \mathrm{kHz}$. This is a very promising result regarding to the complexity of the physics and the rather simplicity of the present method. Beyond $3.5 \mathrm{kHz}$, the PWL attenuation due to the serrations is over-estimated by the simulations. It might be due to the fact that the contribution of oblique gusts $\left(k_{y} \neq 0\right)$ not taken into account here, is no more negligible at these frequencies (contrarily to the straight leading edge case). As a consequence, it could tend to balance the overall level since the spanwise gusts are getting more and more cut-off at higher frequencies. Complementary analysis and discussion about the contribution of oblique gusts to the wavy-edge airfoil response are proposed in the next paragraph. 

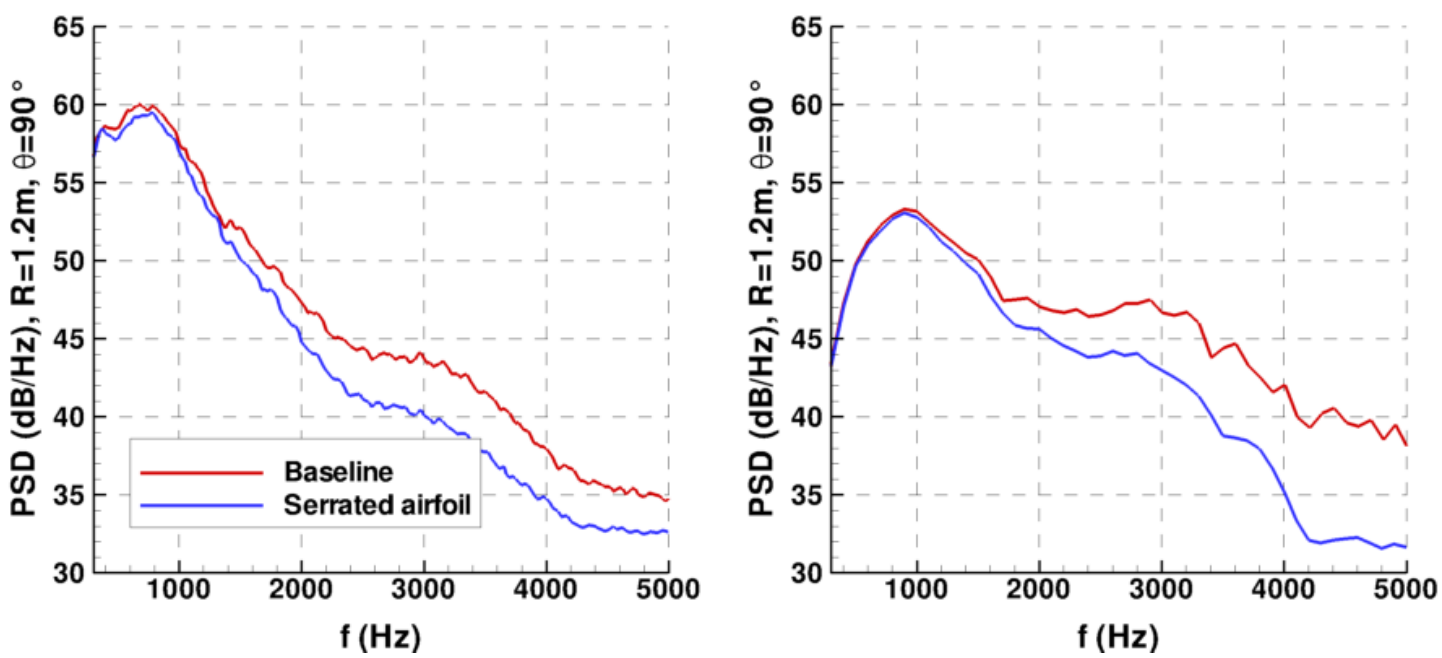

Figure 20. PSD comparison between baseline and serrated airfoils. Experiment (left) and CAA (right).

\section{IV.C. Response to oblique gusts}

The response of a flat plate to an oblique gust can be solved analytically, underlining a dispersion relation ${ }^{27}$ depending on the streamwise wavenumber, the spanwise wavenumber and the Mach number of the mean flow. When an oblique gust satisfies the relation $\left|\tilde{k}_{y}\right|<\left|\tilde{k}_{x}\right| M / \sqrt{1-M^{2}}(\tilde{k}$ are the wavenumbers reduced by half the chord), it is called supercritical and the mode is cut-on. If $\left|\tilde{k}_{y}\right|>\left|\tilde{k}_{x}\right| M / \sqrt{1-M^{2}}$, the gust is called subcritical and the mode is evanescent in the case of an infinite span. This effect is illustrated in figure 21 where snapshots of CAA computations performed using sAbrinA.v0 are presented for a supercritical gust (left) and a subcritical one (right). The subcritical case shows that a pressure disturbance remain confined to the vicinity of the plate.
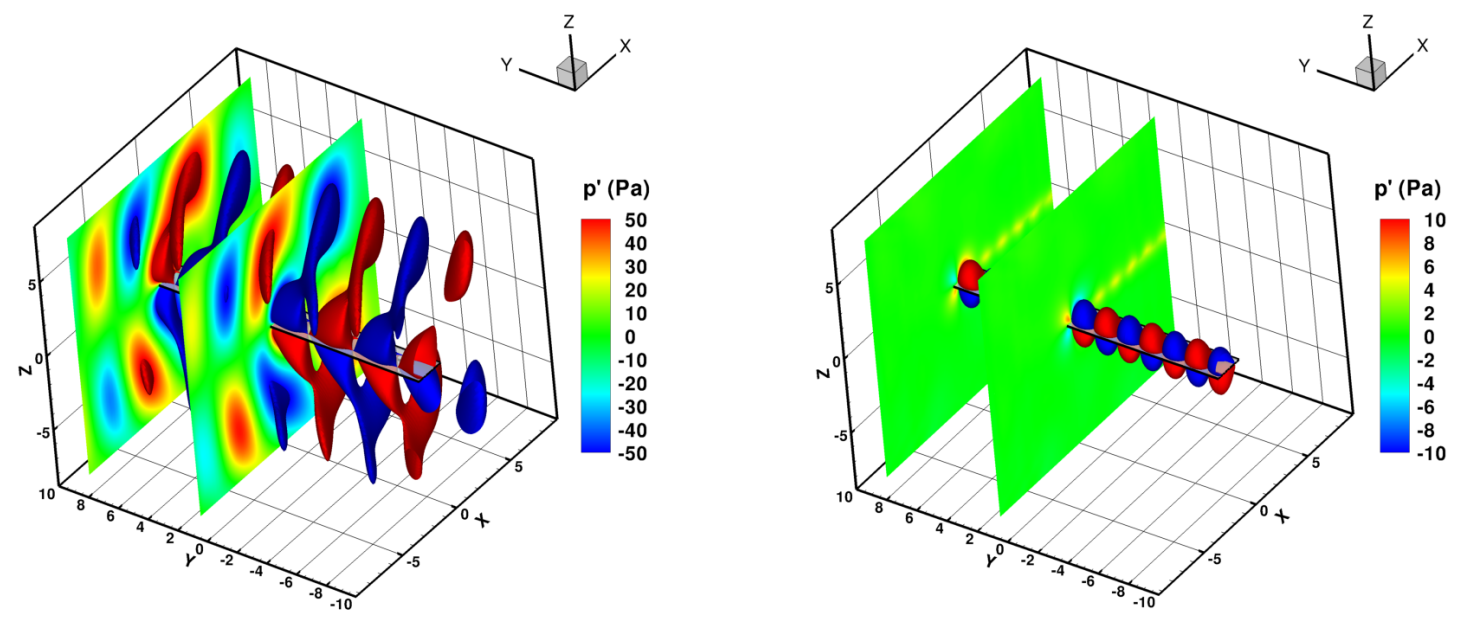

Figure 21. Snapshots of pressure fluctuations for a supercritical (left) and a subcritical (right) gust.

As already discussed in ref. [3], a simplified modeling of the leading edge serrations can be suggested by approximating the sinusoidal geometry by triangular waves (Fig. 22). Thus, it is possible to introduce a lean angle $\gamma$ and to extend the dispersion relation by mean of suited variable transformations. Note that the present analytical model only focuses on the spanwise variation of the chord without changing the direction of the local flow. This is different to the approach proposed by Adamczyk ${ }^{28}$ solving the problem of an 
infinite swept blade with constant chord and for which the convection velocity is inclined with respect to the chordwise direction (whereas it is aligned here). The dispersion relation in our case can be written as:

$$
\Theta^{2}=\left(\frac{\tilde{k}_{x} M}{1-M^{2}}\right)^{2}-\left(\frac{\tilde{k}_{x} M}{1-M^{2}} \tan \gamma+\frac{\tilde{k}_{y}}{\sqrt{1-M^{2}}}\right)^{2}
$$

The standard dispersion relation is recovered by setting $\gamma=0^{\circ}$ in Eq. (9). Roots of the second order equation $\Theta^{2}=0$ can be easily obtained, allowing us to draw the spatial filtering of the gusts as a function of the lean angle, as done in figure 23. For the baseline case, the region of cut-on gusts is centered on the parallel modes $\left(k_{y}=0\right)$, but there are more and more cut-on oblique modes as the streamwise wavenumber (i.e. the frequency) is increasing. This is coherent with the Amiet results plotted in figure 7. For high values of $\gamma\left(\right.$ close to $90^{\circ}$ ), this representation shows that the parallel modes are cut-off and oblique modes previously cut-off by the baseline case are now cut-on. Similar effect is expected for the serrated airfoil and can explain the discrepancies in the CAA results for high frequencies. In particular the oblique gust $k_{y}=2 \pi / \lambda_{s}$ (i.e. $\tilde{k}_{y}=47$ ) should contribute significantly to the radiated noise. Indeed, this wavelength being equal to the serration wavelength, the trated airfoil response is expected to be particularly sensitive (resonance effects) to this spanwise wavenumber and its harmonics.

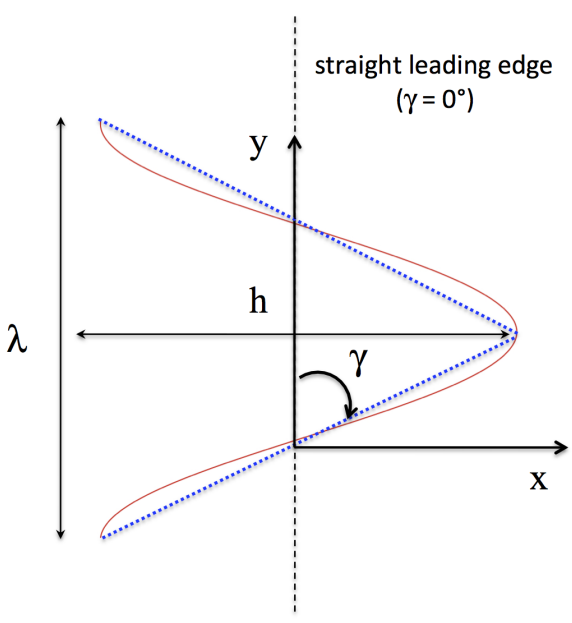

Figure 22. Triangular approximation of the serrations.

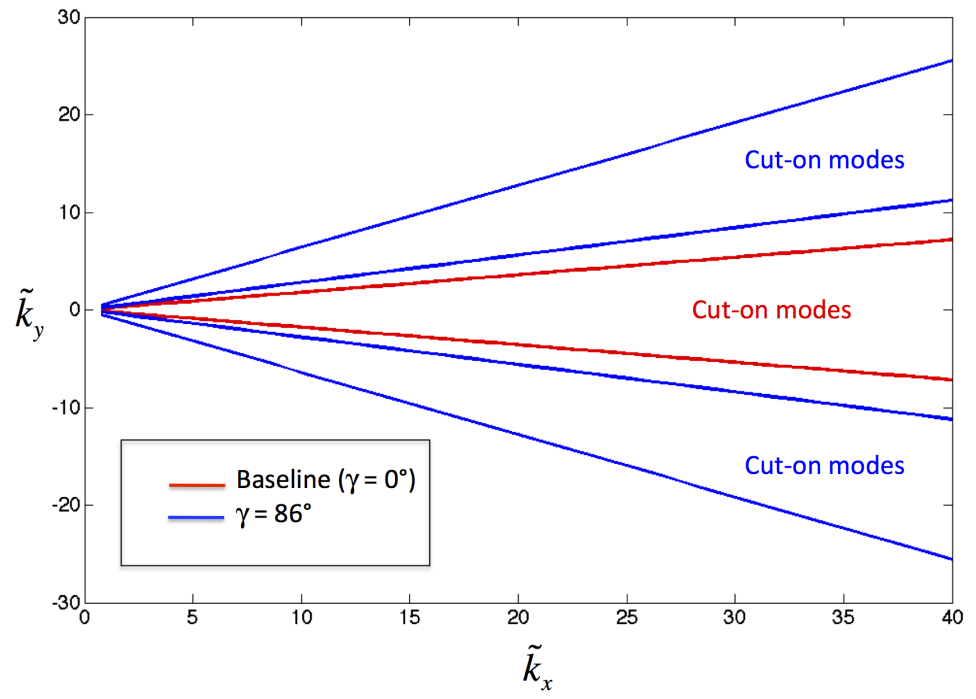

Figure 23. Filtering of the oblique gusts regarding to the lean angle.

\section{Conclusion}

A numerical methodology aiming at predicting turbulence interaction noise on complex airfoil geometries has been presented and applied in this paper. It is based on a CAA code solving the nonlinear Euler equations applied to the disturbances and a synthetic turbulence model fitting a prescribed HIT spectrum. The turbulent velocity field is injected at the inflow of the computational domain by means of Tam's inflow boundary condition. The method has been firstly validated on two dimensional cases against analytical results. The coupling with an integral method solver has been validated for a three dimensional flat-plate and considering only parallel gusts. The method has then been applied to estimate the acoustic response of an isolated NACA651210 airfoil and the effect of sinusoidal leading edge serrations designed by ONERA, assuming a uniform mean flow. The acoustic spectra and noise reduction experimentally achieved have been fairly well reproduced. The deviation on the attenuation slope might be reduced if a more realistic mean flow was used and the low-frequency hump observed in the experimental spectrum might be attributed to additional source mechanisms. The overestimation of the acoustic performances of the serrations at high frequency (beyond 3-4 kHz) should be due to the spanwise gusts contribution neglected in the present computations. A basic theoretical analysis related to the spatial filtering of the gusts in the wavenumber 
space has been proposed to argue this point. The next step of this study will be the realisation of a complementary simulation on the serrated airfoil including oblique gusts, involving a larger spanwise extent and so a huge mesh and CPU time. Preliminary work to speed-up the computation of the source term at the inflow when using a two-wavenumbers spectrum has to be done, as it becomes a major CPU time consumer in the computations. Computations to check the effect of RANS flows on the radiated noise will also be performed. Finally, this methodology will be adapted to the annular cascade benchmark ${ }^{29}$ and then to realistic rotor/stator broadband noise problems.

\section{Acknowledgments}

This study has been supported by the European Commission (FLOCON FP7 project). Authors would like to thank Mat Gruber (ISVR) for having performing and providing the experimental data.

\section{References}

${ }^{1}$ Jacob, M.C., Boudet, J., Casalino, D., Michard, M., "A rod-airfoil experiment as benchmark for broadband noise modeling", Theoretical and Computational Fluid Dynamics, Vol. 19, 2005, pp.171-196.

${ }^{2}$ Gruber, M., Joseph, P., Chong, T.P., "Experimental investigation of airfoil self noise and turbulent wake reduction by the use of trailing edge serrations", Proc. of the 16th AIAA/CEAS Aeroacoustics Conference, AIAA Paper 2010-3803, 2010.

${ }^{3}$ Polacsek, C., Reboul, G., Clair, V., Le Garrec, T., Deniau, H., "Turbulence-airfoil interaction noise reduction using wavy leading edge : An experimental and numerical study", Proc. of Internoise 2011, Osaka (Japan), 2011.

${ }^{4}$ Amiet, R.K., "Acoustic radiation from an airfoil in a turbulent stream", Journal of Sound Vibration, Vol. 41, 1975, pp.407-420.

${ }^{5}$ Amiet, R.K., "Airfoil gust response and the sound produced by airfoil-vortex interaction", Proc. of the 9th AIAA/NASA Aeroacoustics Conference, AIAA Paper 84-2268, 1984.

${ }^{6}$ Lockard, D.P., Morris, P.J., "A parallel implementation of a computational aeroacoustic algorith for airfoil noise", Proc. of the 2nd AIAA/CEAS Aeroacoustics Conference, AIAA Paper 96-1754, 1996.

${ }^{7}$ Lockard, D.P., Morris, P.J., "Radiated noise from airfoils in realistic mean flows", AIAA Journal, Vol. 36(6), 1998, pp.907-914.

${ }^{8}$ Scott, J.R., "Single airfoil gust response problem", Proc. of the 4th CAA Workshop on Benchmark Problems,NASA CP-2004-212954, 2003, pp.45-58.

${ }^{9}$ Golubev,V.V., Mankbadi, R.R., Scott, J.R., "Numerical inviscid analysis of nonlinear airfoil response to impinging highintensity high-frequency gust", Proc. of the 10th AIAA/CEAS Aeroacoustics Conference, AIAA Paper 2004-3002, 2004.

${ }^{10}$ Golubev,V.V., Mankbadi, R.R., Visbal, M.R., Scott, J.R., Hixon, R., "A parametric study of nonlinear gust-airfoil interaction", Proc. of the 12th AIAA/CEAS Aeroacoustics Conference, AIAA Paper 2006-2426, 2006.

${ }^{11}$ Golubev,V.V., Mankbadi, R.R., Hixon, R., "Space-time mapping analysis of airfoil nonlinear interaction with unsteady inviscid flow", AIAA Journal, Vol. 43(10), 2005.

${ }^{12}$ Hixon, R., Golubev, V.V., Mankbadi, R.R., Scott, J.R., Sawyer, S., Nallasamy, M., "Application of a nonlinear computational aeroacoustics code to the gust-airfoil problem", AIAA Journal, Vol. 44(2), 2006.

${ }^{13}$ Hixon, R., Sescu, A., Nallasamy, M., Sawyer, S., "Prediction of noise from realistic rotor-wake/stator-row interaction using computational aeroacoustics", Proc. of the 15th AIAA/CEAS Aeroacoustics Conference, AIAA Paper 2009-3339, 2009.

${ }^{14}$ Hixon, R., Sescu, A., Sawyer, S., "Vortical gust boundary condition for realistic rotor wake/stator interaction noise prediction using computational aeroacoustics", Journal of Sound and Vibration, Vol. 330, 2011, pp. 3801-3817.

${ }^{15}$ Ewert, R., "Slat noise trend predictions using CAA with stochastic sound sources from a random particle mesh method (RPM)", Proc. of the 12th AIAA/CEAS Aeroacoustics Conference, AIAA Paper 2006-2667, 2006.

${ }^{16}$ Dieste, M., Gabard, G., "Synthetic turbulence applied to broadband interaction noise", Proc. of the 15th AIAA/CEAS Aeroacoustics Conference, AIAA Paper 2009-3267, 2009

${ }^{17}$ Salem-Said, A.H., "Large eddy simulation of shear-free interaction of homogeneous turbulence with a flat-plate cascade", PhD Thesis, Virginia Polytechnic Institute and State University, 2007.

${ }^{18}$ Deniau, H., Dufour, G., Boussuge, J.F., Polacsek, C., Moreau, S., "Affordable compressible LES of airfoil-turbulence interaction in a free jet", Proc. of the 17th AIAA/CEAS Aeroacoustics Conference, AIAA Paper 2011-2707, 2011.

${ }^{19}$ Redonnet, S., Manoha, E., Sagaut, P., "Numerical simulations of propagation of small perturbations interacting with flows and solid bodies", Proc. of the 7th AIAA/CEAS Aeroacoustics Conference, AIAA Paper 2001-222, 2001.

${ }^{20}$ Tam, C.K.W., Webb, J.C., "Dispersion-relation-preserving finite difference schemes for computational acoustics", Journal of Computational Physics, Vol. 107, 1993, pp. 262-281.

${ }^{21}$ Tam, C.K.W., Dong, Z., "Radiation and outflow boundary conditions for direct computation of acoustic and flow disturbances in a nonuniform mean flow", Journal of Computational Acoustics, Vol. 4(2), 1996, pp. 175-201.

${ }^{22}$ Tam, C.K.W., "Advances in numerical boundary conditions for computational aeroacoustics", Journal of Computational Acoustics, Vol. 6(4), 1998, pp. 377-402.

${ }^{23}$ Kraichnan, R.H., "Diffusion by a random velocity field", Physics of fluids, Vol. 13(1), 1970, pp. 22-31.

${ }^{24}$ Casper, J., Farassat, F., "A new time domain formulation for broadband noise predictions", International Journal of Aeroacoustics, Vol. 1(3), 2002, pp. 207-240. 
${ }^{25}$ Reboul, G., "Modélisation du bruit à large bande de soufflante de turboréacteur", PhD Thesis, Ecole Centrale de Lyon, 2010.

${ }^{26}$ Gruber, M., Joseph, P., Polacsek, C., Chong, T.P., "Noise reduction using combined trailing edge and leading edge serrations in a tandem airfoil experiment", Proc. of the 18th AIAA/CEAS Aeroacoustics Conference, 2012.

${ }^{27}$ Graham, J.M.R., "Similarity rules for thin aerofoils in non-stationary subsonic flows", Journal of Fluid Mechanics, Vol. 43(4), 1970, pp. 753-766.

${ }^{28}$ Adamczyk, J.J., "The passage of an infinite swept airfoil through an oblique gust", NASA Contractor Report, NASA CR-2395, 1974.

${ }^{29}$ Namba, M., Schulten, J., "Category 4-fan stator with harmonic excitation by rotor wake", Third Computational Aeroacoustics (CAA) Workshop on Benchmark Problems, NASA/CP-200-209790, 2000, pp. 73-86. 